\title{
Recording Electrical Currents across the Plasma Membrane of Mammalian Sperm Cells
}

\author{
Boheng Liu ${ }^{1,2}$, Nadine Mundt ${ }^{3,4}$, Melissa Miller ${ }^{1}$, David E. Clapham ${ }^{5}$, Yuriy Kirichok ${ }^{6}$, Polina V. Lishko ${ }^{1}$ \\ ${ }^{1}$ Department of Molecular and Cell Biology, University of California, Berkeley ${ }^{2}$ Department of Neurobiology, Peking University ${ }^{3}$ Institute for Biology II / \\ Chemosensation Lab, RWTH Aachen University ${ }^{4}$ Research Training Group 2416 MultiSenses-MultiScales, RWTH Aachen University ${ }^{5}$ Howard Hughes \\ Medical Institute, Janelia Research Campus ${ }^{6}$ Department of Physiology, University of California, San Francisco
}

\section{Corresponding Author}

Polina V. Lishko

lishko@berkeley.edu

\section{Citation}

Liu, B., Mundt, N., Miller, M., Clapham, D.E., Kirichok, Y., Lishko, P.V. Recording Electrical Currents across the Plasma Membrane of Mammalian Sperm Cells. J. Vis. Exp. (168), e62049, doi:10.3791/62049 (2021).

\section{Date Published}

February 14, 2021

DOI

$10.3791 / 62049$

URL

jove.com/video/62049

\section{Abstract}

Recording of the electrical activity from one of the smallest cells of a mammalian organism- a sperm cell- has been a challenging task for electrophysiologists for many decades. The method known as "spermatozoan patch clamp" was introduced in 2006. It has enabled the direct recording of ion channel activity in whole-cell and cell-attached configurations and has been instrumental in describing sperm cell physiology and the molecular identity of various calcium, potassium, sodium, chloride, and proton ion channels. However, recording from single spermatozoa requires advanced skills and training in electrophysiology. This detailed protocol summarizes the step-by-step procedure and highlights several 'tricks-of-the-trade' in order to make it available to anyone who wishes to explore the fascinating physiology of the sperm cell. Specifically, the protocol describes recording from human and murine sperm cells but can be adapted to essentially any mammalian sperm cell of any species. The protocol covers important details of the application of this technique, such as isolation of sperm cells, selection of reagents and equipment, immobilization of the highly motile cells, formation of the tight (Gigaohm) seal between a recording electrode and the plasma membrane of the sperm cells, transition into the whole-spermatozoan mode (also known as break-in), and exemplary recordings of the sperm cell calcium ion channel, CatSper, from six mammalian species. The advantages and limitations of the sperm patch clamp method, as well as the most critical steps, are discussed.

\section{Introduction}

Similar to the traditional patch clamp invented by Erwin Neher and Bert Sakmann ${ }^{1}$, sperm cell patch clamp enables interrogation of individual ion channel activity, as well as recording from the activity of the entire ion channel population within the single cell ${ }^{2,3}$. The method allows for the identification of a specific ion channel type under degrees of decoupling from enzymatic intracellular processes. This method is crucial for the determination of ion channel 
activity based on its electrophysiological and pharmacological fingerprints, and hence, provides a reliable identification strategy. The downside of the method is its inability to detect non-electrogenic transporters. Additionally, basic electrophysiological training is helpful to understand the nuances of the protocol. To master the patch clamp technique and apply it to mammalian spermatozoa, we recommend studying basic patch clamp literature ${ }^{4,5}$. In this paper we provide a detailed step-by-step procedure and highlight unique practices that make this technique easy to understand and available to anyone who wishes to practice sperm cell electrophysiology.

Ion homeostasis is an essential physiological function of sperm cells that heavily relies on ion channels and ion transporters to maintain physiologically important ion gradients, vary intracellular calcium, and change transmembrane voltage. Ion channels and ion transporters regulate essential sperm cell functions such as motility, navigation in the female reproductive tract, spermatozoan maturation, and in marine organisms, chemotaxis toward the egg $^{6,7,8,9,10,11,12}$. Sperm motility is a gradually acquired process. Sperm cells are mainly quiescent during their maturation in the testis and during their consequent passage through epididymis. Their motility is restrained by an acidic epididymal environment that leads to an internal acidification of the sperm cell. This impairs the function of the axoneme since it is unable to function below $\mathrm{pH} 6.0^{13}, 14$. However, upon exposure to the seminal fluids or a more alkaline environment, sperm intracellular ion concentrations and cytoplasmic $\mathrm{pH}$ undergo major changes and the spermatozoon becomes motile ${ }^{15,16,17}$. The movement of the sperm flagellum is powered by ATP hydrolysis that supports sliding of axonemal microtubules ${ }^{18}$ and this process is highly $\mathrm{pH}$-dependent ${ }^{14}$. Additionally, flagellar movement is also controlled by an elevation of intraflagellar calcium and CAMP $^{13,19,20,21,22,23,24}$. These factors i.e., sperm intracellular calcium concentration $\left[\mathrm{Ca}^{2+}\right] \mathrm{i}, \mathrm{pH}$, ATP and cAMP are the main regulatory mechanisms allowing for motility changes and their concentrations are tightly regulated by the sperm ion channels and transporters.

Sperm cells are unique in that they express a number of proteins that cannot be found anywhere else in the body. Notable examples are sperm ion channels, such as the potassium channel, Slo3 $25,26,27,28,29$ and the Cationic channel of Sperm, CatSper ${ }^{2,30,31,32}$. The latter is the principal calcium channel of mammalian spermatozoa ${ }^{31}$, and is regulated by intracellular alkalization $2,30,31,32,33,34$. CatSper is also regulated by species-specific cues ${ }^{7,35}$ and is organized in quadrilateral longitudinal nanodomains along the sperm flagellum $36,37,38$. In primates, CatSper is activated by a combination of flagellar alkalinity, membrane depolarization and progesterone $3,39,40,41$, while for murine CatSper activation progesterone is not required $^{2,39}$. Another specific feature of this channel is its multisubunit organization: CatSper is a complex of at least 10 different subunits $31,32,34,37,38,42,43,44,45,46,47$. Such sophisticated structure and specifics of its regulation hindered recombinant expression of CatSper in any known heterologous expression system, and hence physiological characterization of CatSper has been restricted to its native system of expression- the sperm cell. While molecular characterization of CatSper protein was achieved in seminal paper in 2000 by D. Ren et. al. ${ }^{31}$, the ultimate proof that CatSper is a bona fide ion channel was possible only after the introduction of the sperm patch clamp method in $2006^{2}$. Since then this technique allowed for precise 
characterization of many ion conducting pathways in sperm cells ${ }^{9,28,37,39,40,44,46,48-54}$.

The classical and the most straightforward method to study ion channel characteristics- the patch clamp technique- was believed to be inapplicable to sperm cells due to their motility and specific morphology (Figure 1A). Specifically, the miniscule volume of the sperm cytoplasm and sperm plasma membrane's tight attachment to the rigid intracellular structures such as sperm's fibrous sheath and nucleus were the main challenges ${ }^{55}$. These two structural features result in a slim, arrow-shaped cell that is designed to penetrate through highly viscous environments such as eggs' protective vestments, without significant deformation or damage to the plasma membrane.

The first step of the patch clamp method is establishment of the tight seal between a recording pipette (a glass micropipette) and the cell plasma membrane. In order to achieve this, one has to pull enough plasma membrane inside the recording pipette for a mechanically stable gigaseal to form between the plasma membrane and glass. The plasma membrane must be flexible and not rigid (Figure 1B). As mentioned above, the entire surface of the sperm plasma membrane is rather tightly adhered, except for the region known as the cytoplasmic droplet (Figure 1A and Figure 2). Hence, the rigid nature of sperm's plasma membrane was considered to be a main obstacle in obtaining the tight seal or 'gigaseal', so named because $>10^{9}$ ohms are required for good recordings. However, the introduction of the sperm patch clamp technique in $2006^{2}$ removed this barrier and this method could be successfully applied to sperm cells of several mammalian species $2,41,51,56$. This breakthrough has been achieved by focusing on the cytoplasmic droplet $(C D)^{2,8}$, a tiny structure found along the midpiece of the sperm (Figure 1A and Figure 2), and is simply the remnant of the elongated spermatid- a sperm cell precursor from which the head and the tail develop. Functionally, it may help the cell adapt to changes in extracellular osmolarity during ejaculation. The important feature is that the plasma membrane within the $C D$ is flexible enough to be drawn into the pipette to form a gigaohm seal. Thus, the sperm CD is the best part on the sperm surface through which one can achieve a successful gigaseal formation and transition to a wholecell mode which ultimately electrically couples the sperm cell to a patch-clamp amplifier ${ }^{2,8}$. It is worth noting, that previous publications reported successful gigaseal formation at the sperm head, which enables recording in the cellattached configuration $54,57,58,59$. However, the recordings in whole-cell configuration have so far only been reported by performing gigaseal formation at the $C D$ region. This whole-cell mode allows the electrical access to the entire volume of the sperm cells, and therefore, allows detection of ion channel activities located on the sperm flagellum, as well as on the sperm head. For only a few years since its development, the sperm patch clamp technique has resulted in tremendous progress in our understanding of the sperm ion channels and is so far one of the most robust techniques to directly investigate the functionality of the sperm ion channels $^{9}, 28,37,39,40,44,46,48,49,50,51,52,53$ (Figure 1).

Sperm patch clamp varies in some details from the classical patch clamp technique as outlined below. First, most of the sperm plasma membrane is tightly attached to the rigid intracellular structure and hence, spermatozoa have almost no "spare" plasma membrane to be drawn into the pipette. The only region that is flexible is the CD's membrane that resembles plasma membrane of many somatic cells, and therefore, can be easily drawn into the pipette. To form a gigaohm seal with the $C D$, negative pressure is created by 
light suction at the top of the pipette in order to draw a small portion of the sperm plasma membrane into the tip of the micropipette (Figure 1B). This portion of the membrane forms a $\Omega$-shaped invagination into the tip of the pipette and establishes a tight seal with its internal walls.

Second, the cytoplasmic droplet in human and mouse spermatozoa is between 1 and $2 \mu \mathrm{m}$ (Figure 1 and Figure 2). Hence, the application of the patch-clamp technique to such a small object requires high-resolution optics. Most sperm patch-clamp rigs are equipped with an inverted microscope with a differential interference contrast (DIC) or Nomarski optical components (Figure 2 and Figure 3). Using a microscope equipped with DIC optics for sperm patch clamp is highly recommended over more conventional phasecontrast optics, since the spatial information seen in DIC helps achieve superior precision in positioning a patch pipette onto the tiny $C D$. We also suggest using a $60 x$ water immersion objective or similar lens, with numerical aperture of 1.2. This objective has a long working distance $(0.28 \mathrm{~mm})$, which allows observation of free-swimming sperm cells in solution (Figure 2). The objective also has an adjustment collar to adjust to the thickness of the cover slip (variable from 0.13 to $0.21 \mathrm{~mm}$ ). This combination of the long working distance and adjustment collar enables observation through two $0.13 \mathrm{~mm}$ cover slips; one cover slip serves as the glass bottom of the recording chamber, and the $5 \mathrm{~mm}$ coverslip with deposited sperm cells is placed on top. As discussed below, depositing sperm cells on easily exchangeable round $5 \mathrm{~mm}$ coverslips, rather than on the bottom of the recording chamber directly, is a convenient way to load fresh sperm cells into the recording chamber.

Third, the sperm patch clamp rig must be equipped with a low noise patch-clamp amplifier and a digitizer to record tiny (picoampere range) electrical currents and miniscule changes in membrane potential. This equipment must ensure the lowest amplifier noise. The absence of vibration is an essential part of a successful patch clamp recording. Sperm patch clamping requires a drift-free precise micromanipulator that can be attached to the inverted microscope with a micromanipulator platform to ensure better stability than an independent micromanipulator stand (Figure 3A). To test the setup, one should not see any movement of the pipette tip (under 60x magnification) even when a person jumps up and down on the floor near the vibration-isolation table.

\section{Protocol}

All experiments were performed in accordance with $\mathrm{NIH}$ guidelines for animal research and approved by UC Berkeley Animal Care and Use Committee (AUP 2015-07-7742), with every effort made to minimize animal suffering. All described methods are consistent with the recommendations of the Panel on Euthanasia of the American Veterinary Medical Association and IACUC committee. All experimental procedures utilizing human derived samples were approved by the Committee on Human Research at the University of California, Berkeley, IRB protocol number 2013-06-5395.

\section{Making glass micropipettes for whole-cell sperm patch-clamp recording.}

NOTE: The small size of the cytoplasmic droplet requires glass micropipettes with fine tips.

1. For micropipette fabrication, start with borosilicate glass capillaries with an outer diameter $1.5 \mathrm{~mm}$, inner diameter $0.86 \mathrm{~mm}$ and an internal filament. Pull the tip on a micropipette puller (Figure 3B).

2. For shaping and polishing of the pipette tip, position a hot wire in close proximity of the tip for a moment. Perform 
this process of fire-polishing under 100x magnification using a pipette polisher (Figure 3C,D).

3. Ensure that the inner diameter of the pipette tip is $\sim 2$ $\mu \mathrm{m}$ before fire polishing and is reduced to $\sim 0.5 \mu \mathrm{m}$ after proper polishing.

NOTE: Only freshly pulled pipettes made on the day of recording are recommended for use. This avoids the accumulation of dust particles on the pipette tip.

\section{Setting up the rig}

\section{Assembly of the recording chamber}

1. Use a low-volume diamond-shaped perfusion chamber with laminar flow and relatively fast solution exchange rates (Figure 4). Connect the chamber via a manifold to a gravity-fed perfusion system (Figure 5).

2. To perfuse a solution through the recording chamber, assemble a simple self-made gravityfed perfusion system with a polytetrafluoroethylene manifold that connects the perfusion chamber to eight separate perfusion lines.

NOTE: The tubing should not leach plasticizers into the solutions, since such chemicals can significantly impact the normal function of sperm cells $^{60}$ and alter ion channel activity ${ }^{61,62}$. A small diameter polytetrafluoroethylene tubing is highly recommended as the main perfusion tubing.

3. As polytetrafluoroethylene tubing is rather stiff, make flexible connections with high purity silicon tubing fit over the polytetrafluoroethylene tubing. In addition, use syringes (e.g., Luer Lock syringe- type) that lack lubricant, since mineral oil or other lubricant additives can interfere with ion channel recording (Figure 5).

\section{Assembling an agar bridge}

1. To avoid liquid junction potential changes during recordings, keep the environment around the reference electrode stable by using an agar bridge (Figure 4).

2. To make an agar bridge, make an L-shaped glass capillary by bending it under a small Bunsen burner fire and let it cool down.

3. Make a solution of $1 \%$ agarose in $1 \mathrm{M} \mathrm{KCl}$ and heat it in a microwave until the agarose melts and the solution becomes transparent. Carefully fill the Lshaped glass capillary with the above solution to avoid air bubbles and let it cool to room temperature. The agar bridges can be stored in $1 \mathrm{M} \mathrm{KCl}$ for $\sim 2$ months at $+4{ }^{\circ} \mathrm{C}$.

4. To use an agar bridge, fill an $\mathrm{Ag} / \mathrm{AgCl}$ pellet reference electrode with $1 \mathrm{M} \mathrm{KCl}$ and insert the agar bridge carefully to avoid solidified agarose popping out of the glass capillary.

5. Next, insert the gold pin $(2 \mathrm{~mm})$ of the amplifier headstage wire into the reference electrode $2 \mathrm{~mm}$ (gold) slot and insert the end of the L-shaped agar bridge in the perfusion chamber as shown in Figure 4.

\section{Solutions and recipes}

NOTE: All reagents and chemicals must be of the highest purity. All prepared solutions are filtered through a sterile $0.22 \mu \mathrm{m}$ PES filter and stored at $4{ }^{\circ} \mathrm{C}$ for up to one month. It should be noted that the exact adjustment of osmolarity is a prerequisite for successful patch clamping. 
1. Prepare human tubular fluid (HTF) solution as described in Table 1. Adjust the $\mathrm{pH}$ to 7.4 with $\mathrm{NaOH}$. Osmolarity should be $280 \pm 5$ mOsm, measured using a vapor pressure osmometer.

2. Prepare high saline (HS) "bath" or "extracellular" solution as given in Table 2. Adjust the $\mathrm{pH}$ to 7.4 with $\mathrm{NaOH}$. Osmolarity should be $320 \pm 5$ mOsm .

3. Prepare the cesium methanesulfonate "bath" or "extracellular" solution as described in Table 3. Adjust the $\mathrm{pH}$ to 7.4 with $\mathrm{CsOH}$ and the osmolarity to $320 \pm 5 \mathrm{mOsm}$.

4. To prepare the cesium methanesulfonate (CsMeSO3) intracellular "pipette" solution follow Table 4 and adjust $\mathrm{pH}$ to 7.4 with $\mathrm{CsOH}$. Osmolarity should be up to $10 \mathrm{mOsm}$ higher than the HS solution.

\section{Isolation and purification of mammalian spermatozoa}

NOTE: Euthanize C57BL/6 male mice aged 3-6 months by inhalation of $\mathrm{CO} 2$ followed by cervical dislocation. After cervical dislocation, perform tissue collection (cauda or corpus epididymis) from mice immediately.

\section{Isolation of epididymal mouse spermatozoa}

NOTE: Euthanize C57BL/6 male mice aged 3-6 months by inhalation of $\mathrm{CO} 2$ followed by cervical dislocation. After cervical dislocation, perform tissue collection (cauda or corpus epididymis) from mice immediately.

1. Open the lower abdominal area of the mouse with scissors and extract both epididymides.

2. Place them in a $35 \mathrm{~mm}$ cell culture dish filled with $\mathrm{HS}$ solution (high saline solution, see Table 2). Ensure that an aliquot of the HS solution is prewarmed to room temperature before contact with the sperm cells.

3. Transfer the epididymides into a new cell culture dish containing HS solution and thoroughly remove all residual fat.

4. Separate the epididymides into caput, corpus and cauda using a \#15 scalpel blade (Figure 6).

5. Transfer the corpus (or cauda if needed) of each epididymis into a new cell culture dish containing HS solution. Make multiple incisions in the isolated part of the epididymis using a pointed \#11 scalpel blade.

6. Transfer the parts of the epididymides with multiple incisions into a $1.5 \mathrm{~mL}$ microcentrifuge tube containing $1.5 \mathrm{~mL}$ HS solution.

7. Briefly shake sperm cells from the epididymis into the solution using super-fine Dumont type $5 \mathrm{a}$ forceps. Discard epididymides and leave the tube at room temperature for $10 \mathrm{~min}$.

8. Wait until the solid matter (non-sperm cells) sediments to the bottom of the tube, and then transfer the supernatant into another $1.5 \mathrm{~mL}$ microcentrifuge tube.

9. Store the sperm mixture at room temperature with access to air for up to $2 \mathrm{~h}$, during which time the experiments can be performed. Isolated sperm lose their performance $3 \mathrm{~h}$ after isolation.

\section{Capacitation of mouse spermatozoa}

NOTE: All epididymal spermatozoa are suitable for patch-clamp, but only spermatozoa from the cauda epididymis are mature enough to become fertilization competent. Since caudal spermatozoa can undergo 
capacitation, perform experiments, particularly sperm capacitation, using caudal sperm cells.

1. Perform sperm collection on caudal or ejaculated spermatozoa (see steps 3.1.1-4).

2. Take caudae isolated as described in step 3.1.4. and apply multiple incisions as described in step 3.1.5. Transfer the caudae to a $10 \mathrm{~mm}$ cell culture dish with $2 \mathrm{~mL}$ of capacitation solution.

3. Incubate the caudal tissue in this capacitation solution initially for $10 \mathrm{~min}$ at $37{ }^{\circ} \mathrm{C}$ and $5 \% \mathrm{CO} 2$, then discard the tissue and incubate the released sperm cells for another $50-80 \mathrm{~min}$.

NOTE: In vitro capacitation of mouse caudal spermatozoa is achieved by $60-90$ min incubation. Capacitated sperm cells are visually identified based on excessive asymmetric bending of their flagella known as hyperactivation. This type of motility allows spermatozoa to swim in a nonlinear manner.

\section{Collection and purification of human sperm}

NOTE: In this case, fresh semen samples were obtained from a total of 21 healthy volunteers aged $21-38$ and spermatozoa purified by the room temperature swimup technique as described in detail in ${ }^{48,63}$. Briefly, the procedure is as follows:

1. Leave the human ejaculate samples at room temperature for $60 \mathrm{~min}$ to allow for liquefaction before being purified (longer durations may negatively affect sperm quality).

2. Preheat about $7 \mathrm{~mL}$ of $\mathrm{HTF}$ solution to $37^{\circ} \mathrm{C}$ in a $50 \mathrm{~mL}$ centrifuge tube. Visually assess the volume of the ejaculate-if the volume is greater than $1 \mathrm{~mL}$, prepare multiple tubes of HTF solution.
3. Carefully underlay $1 \mathrm{~mL}$ of liquefied ejaculate to the bottom of each tube without lifting strands of semen to the surface of the buffer. The semen-to-HTFinterface should be as clear-cut as possible. Avoid air bubbles.

4. Place the tubes in $a 37^{\circ} \mathrm{C}$ incubator for $1 \mathrm{~h}$ in a stand that holds them at a $45^{\circ}$ angle for maximal surface area. If the incubator is a $\mathrm{CO}_{2}$ incubator, close the cap tightly to prevent acidification of the buffer ( $\mathrm{CO}_{2}$ is not required for this procedure). During the incubation, motile sperm will gradually swim towards the surface of the HTF buffer.

5. After $1 \mathrm{~h}$ collect the uppermost $1 \mathrm{~mL}$ fraction from all samples in a $15 \mathrm{~mL}$ centrifuge tube, thus combining the highest quality, highly motile sperm for patch clamping. Do not attempt to remove all the supernatant-leave several $\mathrm{mL}$ of HTF remaining above the seminal plasma to avoid contamination. The purified cell suspension can be stored at room temperature for several hours.

NOTE: A normal ejaculate should contain at least 15 $x 10^{6}$ sperm cells per $\mathrm{mL}^{64}$, but sperm counts vary widely between samples. The obstacle of a low cell count may be overcome by letting the purified sperm suspension sit for $30-60 \mathrm{~min}$ at room temperature before patch clamping. Under this condition, the cells will gradually accumulate at the bottom of the centrifuge tube and form a visible cell cloud from which you can pipette cells into the recording chamber (see below).

\section{Capacitation of human spermatozoa}

NOTE: In-vitro capacitation of human spermatozoa can be accomplished by $4 \mathrm{~h}$ incubation in capacitation 
solution: $20 \%$ fetal bovine serum, $25 \mathrm{mM} \mathrm{NaHCO} 3$ in HTF or HS buffers ${ }^{48,51}$. Capacitated sperm cells can be visually identified based on their vigorous motility and excessive asymmetric bending of the flagella that allows spermatozoa to swim in a nonlinear manner.

1. Prepare a $2 x$ capacitation solution and mix 1:1 with the sperm suspension.

2. Perform incubation at $37{ }^{\circ} \mathrm{C}$ and $5 \%$ CO2 for a minimum of $4 \mathrm{~h}$. To ensure a high percentage of capacitated cells, incubation time should be no shorter than $4 \mathrm{~h}$.

\section{Preparing coating solution (only needed for human sperm patch-clamp)}

NOTE: An essential step is to lift the attached spermatozoon from the coverslip before break-in. This step is only necessary for human sperm cells and requires coating of the glass coverslip to create a less adhesive glass surface. Coverslip coating reduces the sperm cells' probability of sticking to the coverslip and allows human spermatozoa to be lifted from the glass coverslip after successful gigaseal formation.

1. Dilute $200 \mu \mathrm{L}$ of the ejaculate in $5 \mathrm{~mL}$ of $\mathrm{HS}$ solution in $15 \mathrm{~mL}$ centrifuge tube.

2. Spin down at $300 \times g$ for $5 \mathrm{~min}$ and remove supernatant.

3. Resuspend the pellet in $1 \mathrm{~mL}$ of HS solution and transfer to a microcentrifuge tube.

4. Sonicate for $10 \mathrm{~min}$ at $25{ }^{\circ} \mathrm{C}$ using a water-filled sonication bath.

5. Spin down at $10,000 \times g$ for $5 \mathrm{~min}$.

6. Transfer the supernatant to a fresh microcentrifuge tube and use it for coating (instructions below).

\section{Recording ion conductance from the whole sperm plasma membrane.}

\section{Attaching sperm to the coverslip.}

NOTE: Before the patch-clamp recording, spermatozoa are plated onto $5 \mathrm{~mm}$ round cover slips.

1. If working with human cells, briefly dip the coverslips into the prepared coating solution using sharp forceps.

2. Place four cover slips into a single well of a 4-well plate and cover with $300 \mu \mathrm{L}$ of HS solution. Prevent the cover slips from floating by taping them to the bottom of the 4-well plate, pushing them with the plastic tip of a pipettor.

3. Gently resuspend the concentrated suspensions of human (step 3.3.5) or mouse spermatozoa (step 3.1.9) from the storage tube (20-50 $\mu \mathrm{L}$ of concentrated sperm) in $300 \mu \mathrm{L}$ of HS solution above the coverslip.

4. Ensure that spermatozoa accumulate at the bottom of the well where their heads will attach to the coverslip and their flagella will vigorously beat in the solution just above the cover slip. It is important to allow spermatozoa to sediment onto the coverslip for about $10 \mathrm{~min}$ at room temperature before recording. NOTE: If human spermatozoa attach poorly, go back to step 5.1.1 and dilute the prepared coating solution with HS solution (1:20 to up to 1:2). This step must be adjusted to sperm samples from different human donors based on the variable sperm motility that is common in human sperm preparations.

\section{Placing the cover slip}


1. Take one coverslip with slightly adhered cells from the well and place into a diamond-shaped well of the recording chamber containing HS solution (Figure 4).

2. Turn on the perfusion system (Figure 5) filled with HS solution to rinse the chamber and remove debris and excess detached spermatozoa from the chamber. This will increase the probability that the recording pipette stays clean when it reaches the cells. This step is helpful when working with noncapacitated cells that tend to stick to the coverslip stronger.

NOTE: If recording from capacitated sperm, one must avoid turning on the perfusion immediately after a fresh cover slip is placed into the chamber. Capacitated spermatozoa have vigorous motility and only loosely attach to the coverslip. Therefore, to ensure that the largest number of capacitated sperm are available, it is important to wait $\sim 10 \mathrm{~min}$ and let capacitated spermatozoa adhere to the coverslip before turning on perfusion. Once the appropriate capacitated cell is chosen and a gigaseal is formed, the perfusion can be turned back on.

\section{Selection of a sperm cell for patch-clamp recording.}

1. Find a suitable sperm cell with a cytoplasmic droplet using 600x magnification (see below). This is done using a $60 \mathrm{x}$ water immersion len as described in the methods with a 10x magnification eyepiece. In sperm cells isolated from corpus epididymis, the $C D$ is usually located close to the center of the midpiece. In caudal cells, the CD can usually be found close to the annulus (Figure 2C). For human sperm, the CD is located in the neck region (Figure 2A,B).
NOTE: Additionally, the pull-out 1.6x magnification option of the microscope can be used to closely examine sperm morphology (magnification 960x).

2. Ensure that the cytoplasmic droplet is oval and has a slightly elongated (Figure 2G), spindle-like shape. CDs that appear very round and enlarged are often fragile and unsuitable for patching (Figure 2D,F).

3. Select a spermatozoon that is motile with the head attached to the coverslip, such that the sperm cell is partly fixed, but the $C D$ and the rest of the flagellum continues to move with flagellar beating. Ensure that the head of the sperm is loosely attached to the coverslip so that it rotates a little bit as the flagellum moves from side to side.

NOTE: Loose attachment is important since after formation of the gigaohm seal and before the transition into the whole-cell mode, the spermatozoon must be lifted from the coverslip into the solution.

\section{Forming a gigaseal}

NOTE: To record monovalent CatSper currents in the whole-cell mode, pipettes are filled with Csmethanesulfonate (also referred to as pipette or intracellular) solution (Table 4) - this yields a pipette resistance of 11-17 $\mathrm{M} \Omega$ (Figure 7A), as automatically calculated by the amplifier upon applying a voltage step from $0 \mathrm{mV}$ to $10 \mathrm{mV}$. Pipettes can also be filled with other solutions depending on the application. It is recommended that solutions are made with mobile anions such as methanesulfonate, $\mathrm{Cl}^{-}$, aspartate or similar ions to reduce pipette resistance. The osmolarity of the pipette solution should be up to $10 \mathrm{mOsm}$ higher than the bath solution. Slightly higher tonicity of the pipette solution helps to keep the access resistance into 
the sperm cells as low as possible during patch-clamp recording.

1. After visual selection of a sperm cell with a proper morphology (Figure 2G), fill the micropipette with a pipette solution (Table 4) and secure it into the pipette holder.

2. In order to keep the pipette tip clean from debris, apply positive pressure to the pipette using the Utube shaped assembly to ensure that the pipette solution flows out of the tip after it is immersed into the extracellular solution, also referred to below as the "bath" solution (see Table 2).

NOTE: If conditions permit, the formation of the seal under constant perfusion is highly advised, as this condition ensures the cleanest pipette tip.

3. Lower the pipette down and immerse its tip into the bath solution (Table 2). At this time, pipette resistance can be measured (Figure 7A).

4. In order to clearly visualize the cell, position the tip of the pipette above the CD with the opening of the tip aligned diagonally (approximately $45^{\circ}$ ) toward the CD.

5. Quickly lower the tip of the pipette toward the CD to be in the same focal plane, within a few $\mu$ m of the CD.

6. As soon as the tip of the pipette touches the $C D$, apply negative pressure to the pipette using the "mouthpiece" to move part of the droplet into the tip and form a gigaohm seal - also known in electrophysiology as a "suction event". Usually, after initial contact with the pipette tip, the negative pressure in the pipette can be maintained up to a minute to gradually achieve a gigaohm seal.
7. After successful formation of the gigaohm seal (> 4-20 $G \Omega$ ), lift the spermatozoon from the coverslip (Figure 7B).

NOTE: This step is not required for rodent sperm cells due to their length; however, partial detachment of the sperm flagellum is beneficial to alleviate potential pipette drift. Human sperm detachment is an essential step, since the CD is small $(1 \sim 3 \mu \mathrm{m})$; if the cell is left attached to the coverslip, even a slight drift of the pipette during the experiment can disrupt the CD. After the spermatozoon is lifted, its flagellum normally continues to beat, while the cell is attached only to the micropipette.

\section{Break-in and transition into the whole-cell mode.}

1. Compensate stray capacitance transients using the amplifier's compensatory mode before transitioning to the whole-cell mode (Figure 7B). To initially observe capacitance transients, hold the membrane potential at $0 \mathrm{mV}$ and apply $10 \mathrm{mV}$ pulses using the "Membrane Test" tool (Figure 7B).

2. Perform a break-in and transition into the whole-cell mode by applying short (1 ms) gradually increasing (430-650 mV, $~ 50 \mathrm{mV}$ increment) voltage pulses combined with a very light suction (Figure 7C).

NOTE: To apply break-in pulses, use the previously programmed break-in protocol within the patch clamp software. The break-in voltage pulses are applied to the spermatozoon using the high voltage command input (rear-switched) on the back of the amplifier.

3. After application of each break-in voltage pulse, launch the Membrane Test tool to check whether larger capacitance transients appear. 
NOTE: The presence of large capacitance transients

(Figure 7C) indicates that the break-in has occurred, and the entire capacitance of the cell is being measured $(\sim 1 \mathrm{pF}$ for human sperm and $\sim 2.5 \mathrm{pF}$ or more for murine sperm).

4. Fit the large capacitance transients using the Membrane Test Tool to determine the capacitance of the whole cell as well as its access resistance.

NOTE: The access resistance should be as low as possible for efficient perfusion of the interior of the sperm cell with the micropipette solution, as well as for reliable voltage clamp of the sperm plasma membrane. Access resistance is usually $25-30 \mathrm{M} \Omega$ and 50-70 M $\Omega$ for $\mathrm{Cs}^{+} / \mathrm{K}^{+}$- and NMDG- based intracellular solutions, respectively.

5. After successful break-in, proceed with the planned whole cell patch-clamp experiments, such as applying various bath solutions (Figure 8) containing different compounds or measuring channel activities using voltage-step (Figure 8,

Figure 9) or voltage-ramp protocols. If the break-in was not successful, return to step 6.4.1. by choosing a fresh micropipette and select another appropriate sperm cell.

\section{Representative Results}

The sperm patch clamp method allows for direct recording of the CatSper channel.

As mentioned above CatSper recordings were performed by establishing a high resistance (gigaohm) seal between the patch pipette and mammalian spermatozoon at its cytoplasmic droplet. Upon breaking in and transitioning into the whole-cell mode, full electrical access to the entire body of the sperm cell and its interior, including sperm head and flagellum is obtained ${ }^{2,8,39,51}$. This condition ultimately allows recording from any active ion channel located on the sperm plasma membrane. Bath nominally divalent-free (DVF) solution containing either cesium or sodium as the main permeant ion is preferable for recording of monovalent CatSper currents ${ }^{2,8,39,51}$. While the CatSper channel conducts divalent ions such as $\mathrm{Ca}^{2+}$ and $\mathrm{Ba}^{2+}$, they are moving through the CatSper pore at a much slower rate, resulting in barely detectable conductances of a few picoamperes $(\sim 10-20 \mathrm{pA})^{2,8,39,51}$. Hence, measuring monovalent and, therefore, larger currents, through the CatSper channel is a more convenient way to assess the current (Figure 8). It is important to note that CatSper is also permeable to potassium; therefore, the CatSper channel must be blocked, or CatSper-deficient sperm cells used in situations where one wants to study only sperm cell potassium channels $2,3,8,28,65$. By varying the ion composition of the pipette and bath solution, one can selectively exclude certain ion channels, while creating conditions for selective recording from only specific ion channel type(s). For example, addition of $\mathrm{Cs}^{+}$into the pipette solution results in blocking ion permeability through sperm potassium channels.

\section{The CatSper channel is regulated differently among mammalian species.}

Sperm cells of different species are diverse in their morphology and internal regulatory pathways ${ }^{66}$. It is no surprise that their ion channels are also regulated uniquely in ways that reflect the specialized microenvironments of the male and female reproductive tracts. The sperm patch-clamp method has been successfully applied to six mammalian species: murine ${ }^{2}$, rat $^{56}$, human ${ }^{39,51}$, bovine, boar, and macaque ${ }^{41}$ as shown in Figure 9. For these experiments sperm cells from adult male rhesus macaques 
[Macaca mulatta] were obtained from the California National Primate Research Center in compliance with standards of the Association for Assessment and Accreditation of Laboratory Animal Care International (AAALAC) under approved animal protocols by the University of California, Davis as described $\mathrm{in}^{41}$; and all studies were conducted in accordance with the U.S. National Institutes of Health Guide for the Care and Useof Laboratory Animals. Bull and boar semen were obtained as by-products exempt from specific IACUC approval from the UCD Department of Animal Science facilities and all animals were maintained in AAALACapproved facilities. Bull and boar semen can also be obtained from commercial sources.

Primate (Rhesus macaque) and human spermatozoa showed similar CatSper channel properties and regulation. Interestingly, progesterone activation of CatSper seems to be unique to primate spermatozoa (Figure 9 and ${ }^{41}$ ), as boar, bull, and rodent sperm did not display any progesterone stimulated alteration of their CatSper currents. In bull and boar spermatozoa, even basal CatSper channel activity was below detectable limits (Figure 9), suggesting that in these species, calcium influx and consequent hyperactivation is driven by other channels/transporters, or that a different natural stimulator is needed for activation of their CatSper channels. In all sperm species mentioned here, including bull and boar sperm cells, the full electrical access to the interior of the sperm cells was obtained and cells were recorded in the whole-cell mode, as was evident by the appearance of the large capacitance artifacts upon breaking-in (Figure 7). This condition permits easy recording of the functional CatSper channel, and its absence from boar and bovine spermatozoa indicate that either this channel is blocked by a yet unknown endogenous inhibitor present in the sperm cells of these species or requires a specific modulator to be activated. However, these are preliminary experiments and additional experiments will be required for boar and bull sperm cells to ensure functional importance of CatSper channel in these species. This broad spectrum of sperm ion channel diversity among species could be related to the sperm to egg size ratio, the relation between sperm size and the egg protective vestments, or serve as a barrier to fertilization by other species $^{66}$. 

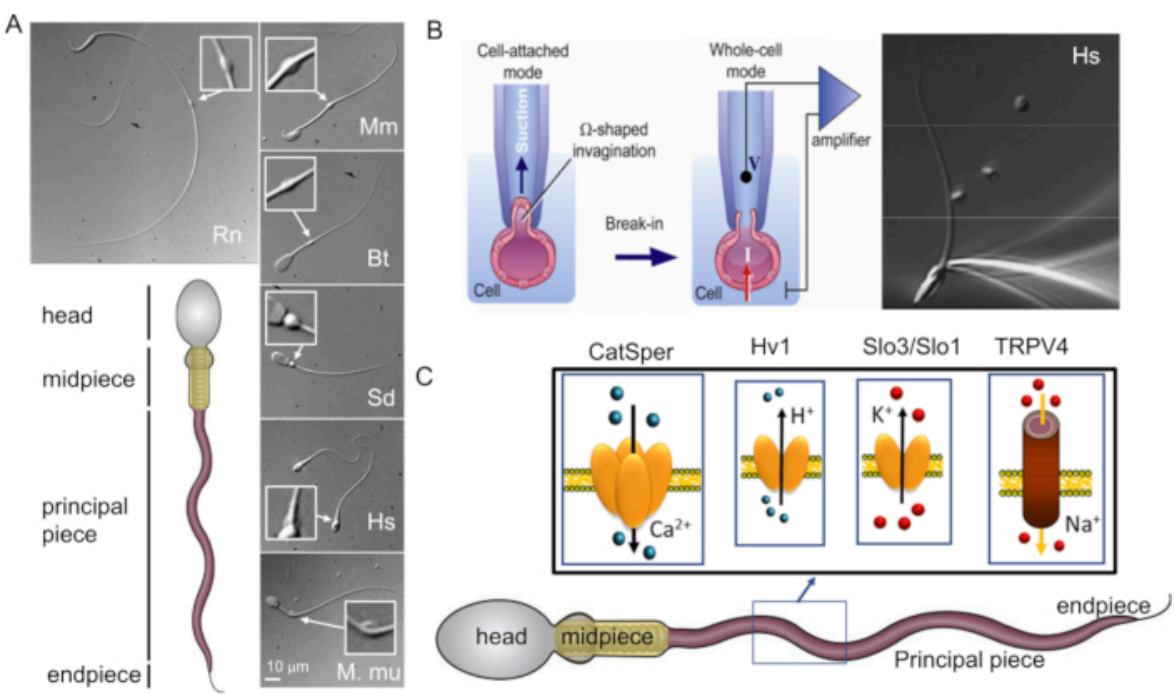

Figure 1: Mammalian sperm morphological diversity. (A) Bottom panel: schematic representation of a spermatozoon; cellular compartments are labeled. Top panels: DIC images of spermatozoa from different species in clockwise: rat (Rn; Rattus norvegicus); mouse (Mm; Mus musculus); bull (Bt; Bos taurus); boar (Sd; sus scrofa domesticus); human (Hs; Homo sapiens), and rhesus macaque (Mmu; Macaca mulatta). The scale bar applies to all DIC images. Inserts indicate cytoplasmic droplets. (B) Patching of the mammalian sperm cells. To achieve successful seal formation between the pipette tip and the plasma membrane, part of the plasma membrane is gently sucked into the pipette tip. Transfer to whole-cell mode is performed by rupturing the plasma membrane between the tip and the cell (this figure has been reproduced from ${ }^{8}$ ). Right panel: human sperm cells attached to a recording micropipette. (C) Schematic representation of human spermatozoon and some of the flagellar ion channels studied in human sperm cells with the patch clamp method, as well as the ions they conduct. CatSper- calcium ion channel ${ }^{39,51}$; Hv1- proton channel ${ }^{51,56,67}$; Slo3/Slo1- potassium channels ${ }^{50,53,65,68}$; TRPV4- transient receptor potential cation channel vanilloid type $4^{48}$. Please click here to view a larger version of this figure. 

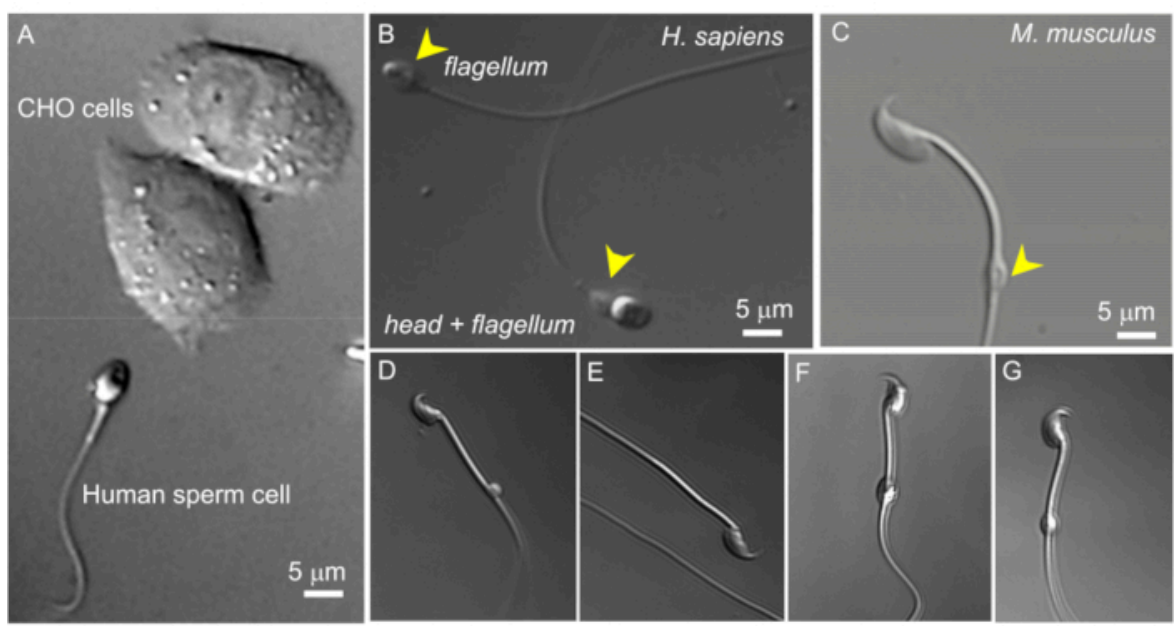

Figure 2: Sperm size and variable morphology of cytoplasmic droplets. The DIC images of intact live sperm cells.

(A) Comparison of the size of a human sperm cell (bottom) and two CHO cells (upper). (B) Intact human (Homo sapiens) spermatozoon (bottom) and a headless sperm cell (flagellum, upper). Cytoplasmic droplets are indicated by yellow arrowheads; this figure has been reproduced from ${ }^{8}$. (C) Intact murine (Mus musculus) spermatozoon with the normal shaped cytoplasmic droplets (CD) indicated by the yellow arrowhead. (D-G) Epididymal murine sperm cells have cytoplasmic droplets of different sizes and shapes; only (C) and (G) are suitable for patch-clamp. (D) CD is microscopic and one-sided; (E) CD is missing; (F) CD has particles inside that may clog the recording pipette; (G) CD is smooth, uniform, and not swollen. Forming a gigaseal with this type of CD will likely result in a successful recording. Please click here to view a larger version of this figure. 


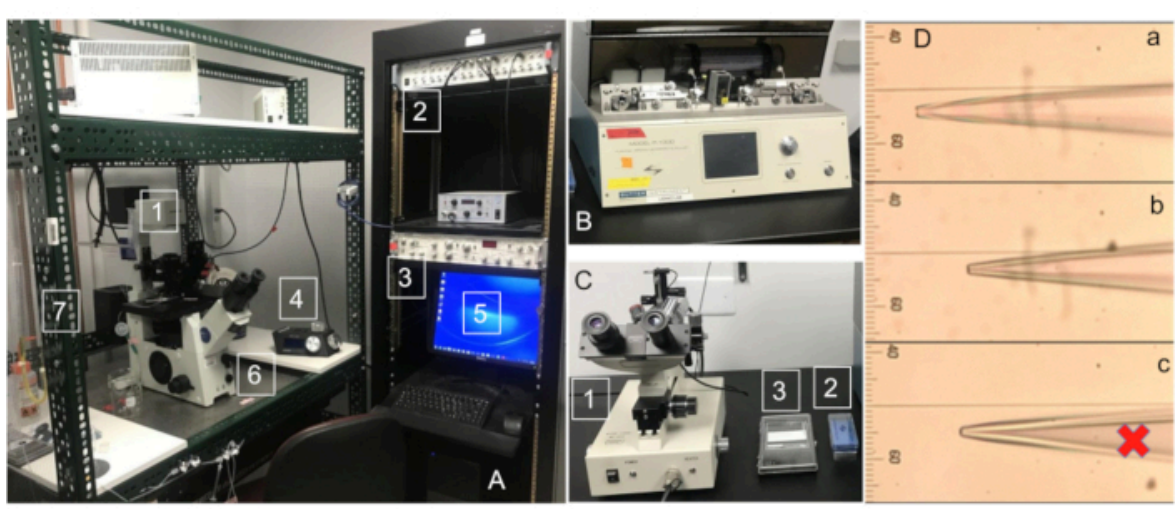

Figure 3: Sperm patch clamp rig components. (A) Typical sperm electrophysiology rig with essential components:

(1) inverted microscope; (2) low noise digitizer; (3) amplifier; (4) low drift micromanipulator that is coupled to the inverted microscope with a micromanipulator platform; (5) PC computer; (6) a vibration-damping air table; (7) Faraday cage to shield the setup from ambient electrical interference. It is essential that all electrically powered components of the rig, including computer keyboard and mouse, produce low or no electrical $(50 \mathrm{~Hz}$ or $60 \mathrm{~Hz})$ noise and that all components of the rig are properly grounded. (B) Micropipette puller used for recording pipette fabrication. (C) (1) microForge used for pipette firepolishing; (2) Borosilicate glass capillaries with outer diameter $1.5 \mathrm{~mm}$, inner diameter $0.86 \mathrm{~mm}$ and an internal filament; (3) pipette collection box. (D) Stages of successful pipette fire-polishing: (a) Unpolished pipette with the inner diameter of $2 \mathrm{~mm}$; (b) Fire-polished pipette with an inner diameter of $0.5 \mathrm{~mm}$; (c) Over-polished sealed pipette not suitable for recording. Please click here to view a larger version of this figure. 

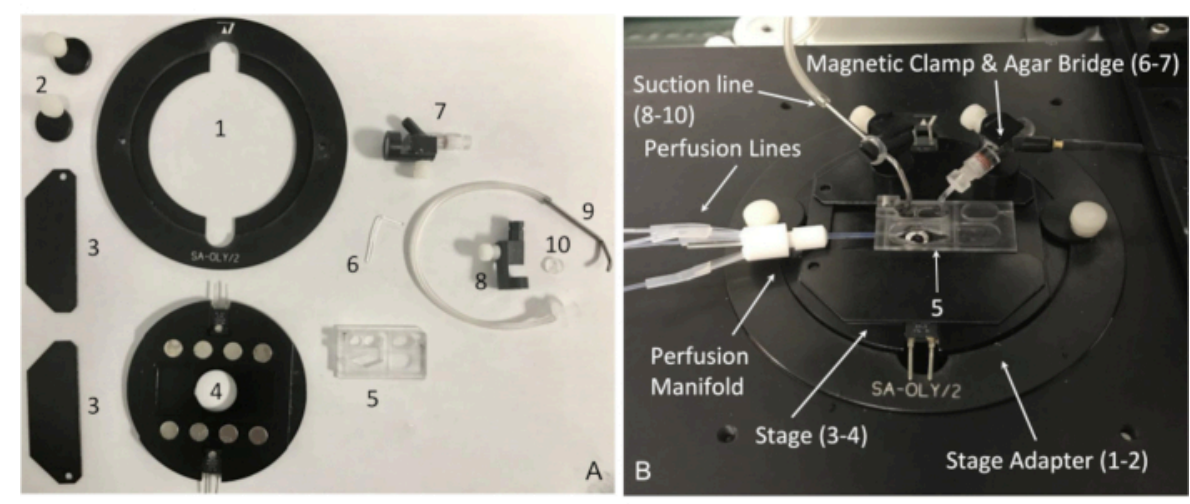

Figure 4: Components of the recording chamber system and its assembly. (A) Essential components of the recording chamber system: (1) microscope stage adapter for series 20 platforms with (2) two stage holding clamps; (3-4) PM series magnetic heated platform with (3) magnetic clamps to hold the perfusion chamber; (5) perfusion chamber; (6) agar bridge; (7) magnetic clamp, reference electrode with $2 \mathrm{~mm}$ jack to $\mathrm{Ag} / \mathrm{AgCl}$ pellet; (8) magnetic holder (MAG-1) for the suction line; (9) suction tube; (10) suction tube O-holder. (B) Assembled recording chamber system with indicated components from (A). Please click here to view a larger version of this figure.
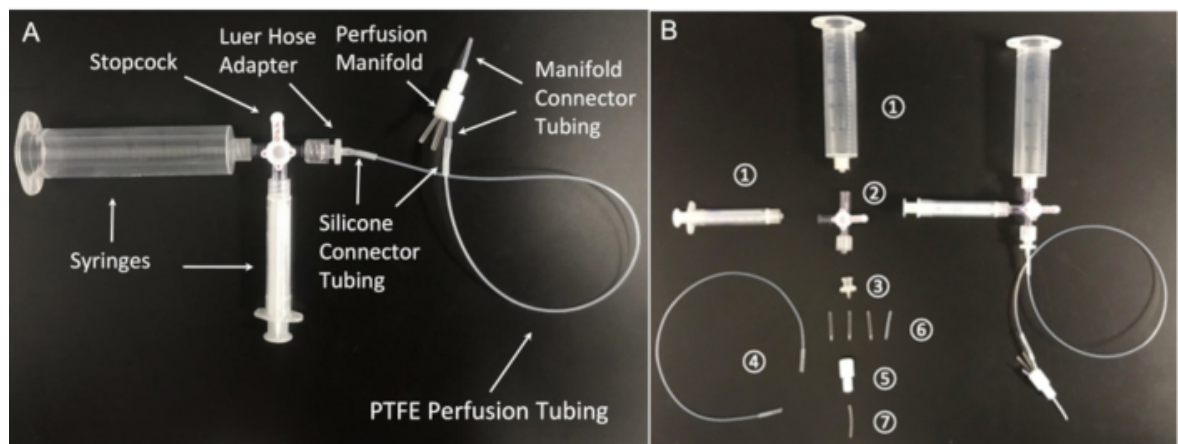

Figure 5: Components of the perfusion system. (A) Assembled perfusion line and (B) its essential components: (1) $20 \mathrm{~mL}$ and $3 \mathrm{~mL}$ syringes; (2) stopcock with Luer connections; 4-way; male lock; (3) female luer hose barb adapter, 1/16"; (4) Polytetrafluoroethylene (PTFE) perfusion tubing (Microbore PTFE Tubing, 0.022" ID × 0.042" OD); (5) Polytetrafluoroethylene 8-position perfusion manifold; (6) Silicone connector tubing (platinum-cured silicone tubing, 1/32" ID × 3/32" OD); (7) Manifold connector tubing (PTFE Tubing, 1/32" ID × 1/16" OD). Please click here to view a larger version of this figure. 


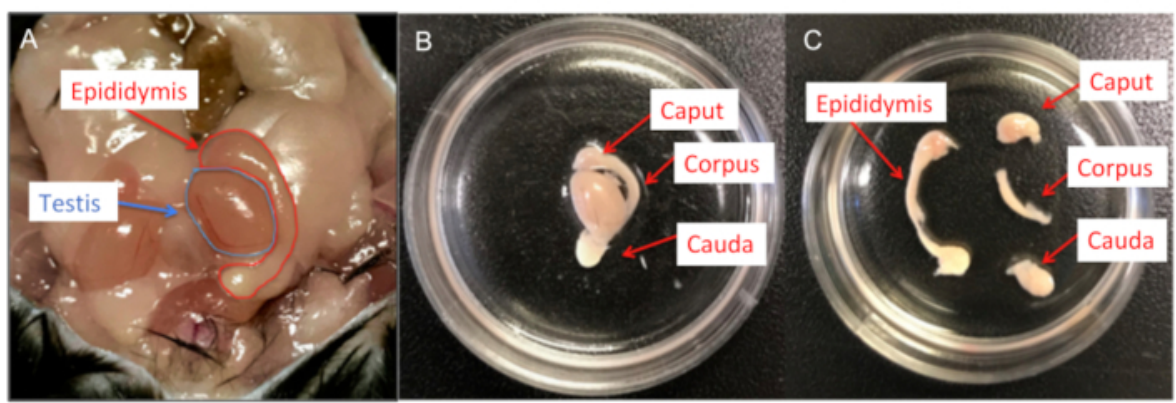

Figure 6: Male mouse dissection. (A) Murine male reproductive organs; both testis and epididymis are shown. (B) The epididymides are transferred into a $35 \mathrm{~mm}$ cell culture dish containing HS solution and the residual fat and vas deferens removed. (C) Each epididymis is then divided into caput, corpus and cauda using a \#15 scalpel blade. Please click here to view a larger version of this figure. 


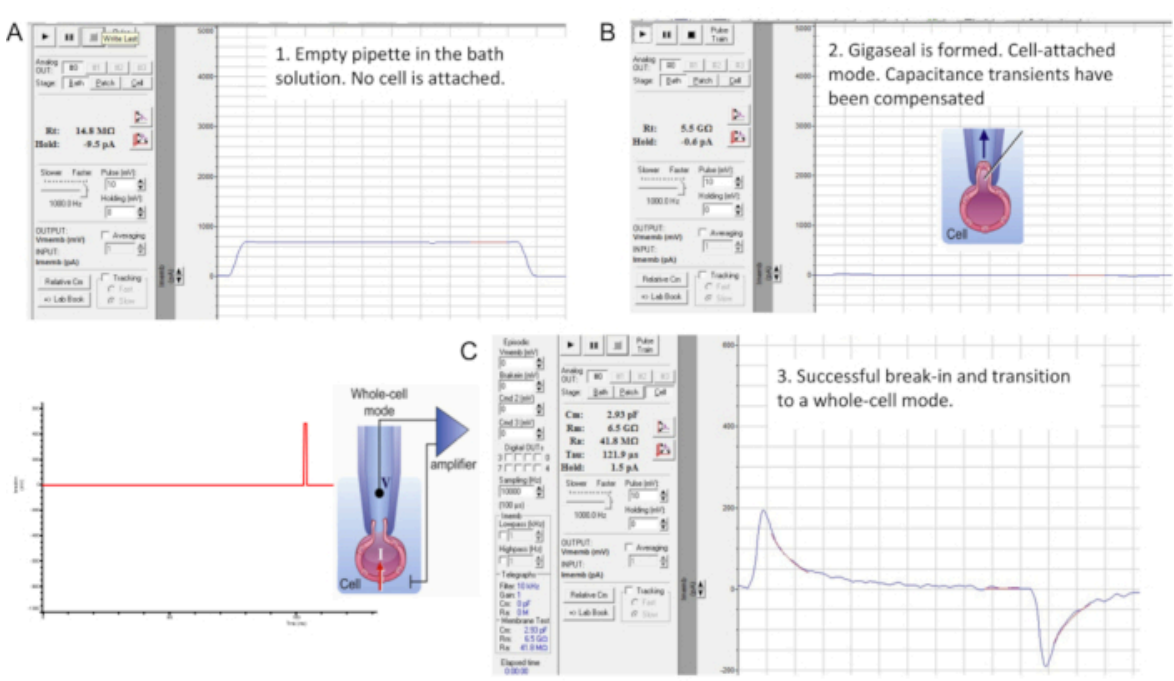

Figure 7: Gigaseal formation and break-in with the murine sperm cell. The interface of the "Membrane Test" tool of the commercial patch clamp software. Three stages of sperm patch clamping: (A) recorded pipette is immersed in a bath HS solution producing a pipette resistance of $14.8 \mathrm{M} \Omega$; (B) A gigaseal is formed (resistance is $4.7 \mathrm{G} \Omega$ ), capacitance transients are compensated, and the spermatozoon is lifted from the coverslip; (C) Transition into whole-cell mode. Breakin and transition into the whole-cell mode is performed by applying short (1 ms) gradually increasing (430-650 mV, $50 \mathrm{mV}$ increment) voltage pulses combined with a light suction, as shown on the left. Break-in has occurred as evident from the appearance of the large capacitance transients that reflect the entire capacitance of the cell ( 2.93 $\mathrm{pF}$ for this sperm cell). Please click here to view a larger version of this figure. 


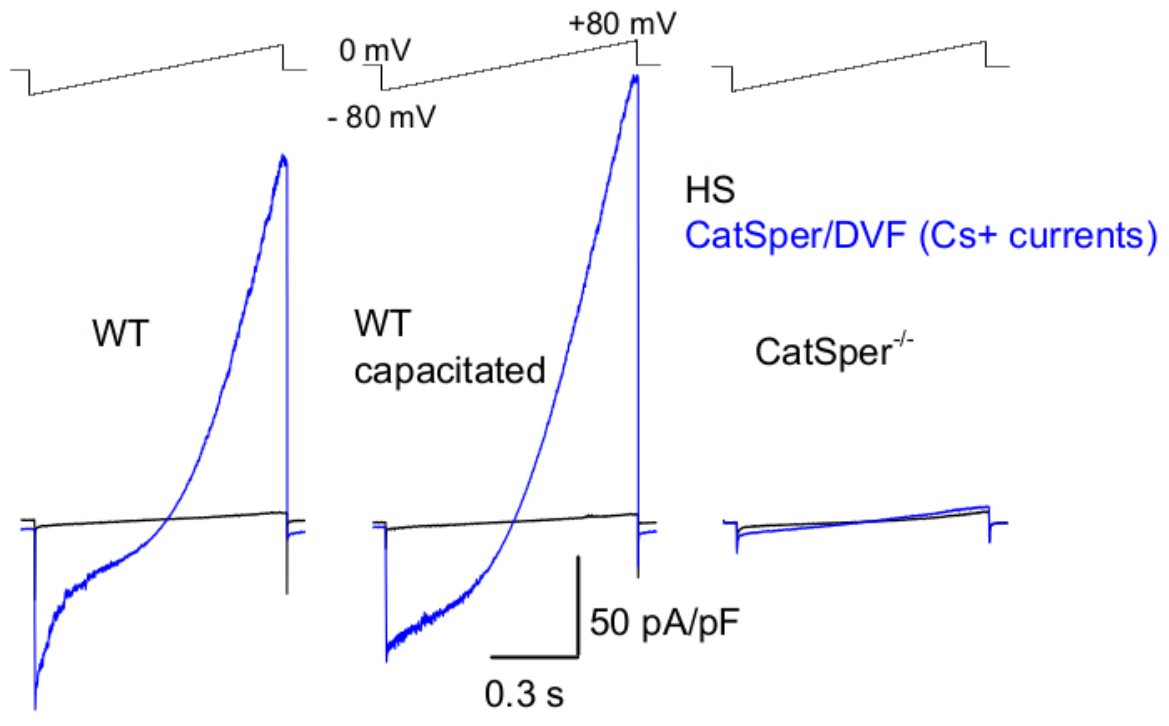

Figure 8: Murine CatSper recording from wild type (WT) cauda epididymal, capacitated and CatSper knockout spermatozoa. To record monovalent CatSper activity, a ramp protocol is applied every $5 \mathrm{~s}$ and CatSper currents elicited by voltage ramps from a holding potential of $0 \mathrm{mV}^{39,51}$. Voltage ramps (-80 mV to $80 \mathrm{mV} ; 850 \mathrm{~ms}$ ) are applied in HS and nominally divalent-free solution (DVF). Data were sampled at $2-5 \mathrm{kHz}$ and filtered at $1 \mathrm{kHz}$. Baseline currents are recorded in HS solution, which produces no CatSper current due to inhibition by high extracellular magnesium ${ }^{39,51}$. Baseline currents are useful to estimate the leak conductance (non-ion channel pathways). Representative, $\mathrm{Cs}^{+}$whole-cell CatSper current densities (pA/pF; blue) recorded from caudal WT murine sperm cells (noncapacitated; left and capacitated; middle) and CatSper-deficient caudal murine sperm cells (right). Currents were elicited by voltage ramps from a holding potential of $0 \mathrm{mV}$ and ramps were applied from $-80 \mathrm{mV}$ to $80 \mathrm{mV}$ in $\mathrm{HS}$ and nominally divalent-free solution. Baseline currents (black) recorded in HS solution. To obtain current densities, CatSper current amplitudes were normalized to cell capacitance (pA/ pF). Please click here to view a larger version of this figure. 


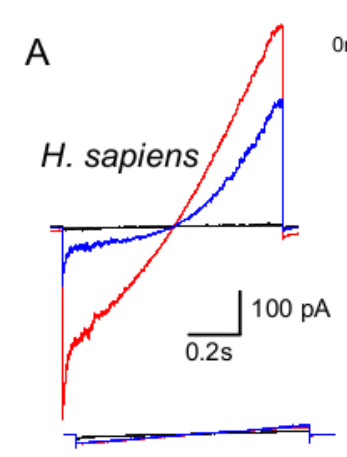

B. taurus

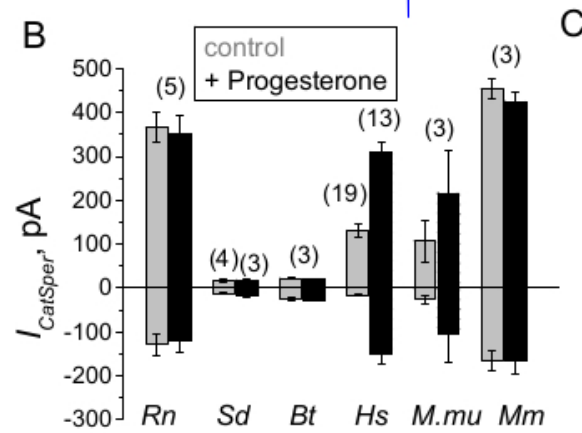

C

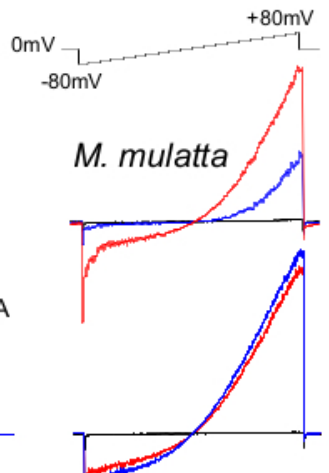

R. norvegicus

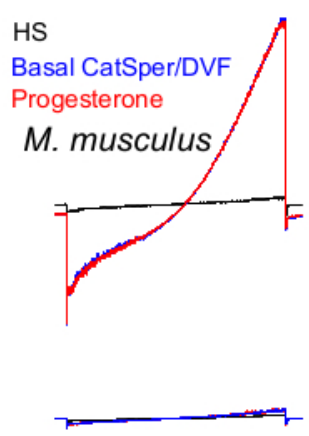

S. domesticus

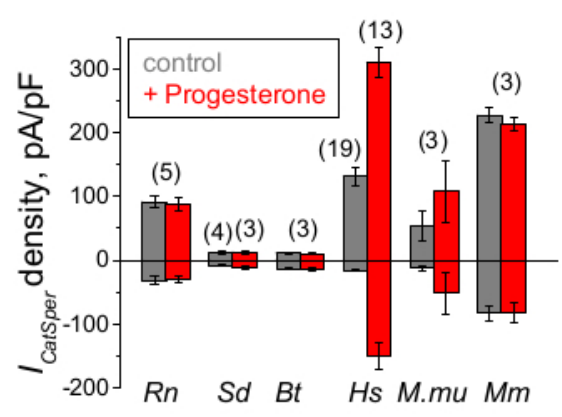

Figure 9: Progesterone regulation of CatSper in different mammalian species. (A) Representative CatSper current elicited from sperm cells of different species by a voltage ramp protocol as indicated. Species: human (Hs; $H$. sapiens); rhesus macaque (Mmu; M. mulatta), mouse (Mm; M. musculus), bull (Bt; B. taurus); rat (Rn; R. norvegicus); boar (Sd; $S$. scrofa domesticus). CatSper currents in the absence (blue) and presence (red) of $1 \mathrm{mM}$ progesterone were recorded, as well as the basal currents in HS solution (black). (B) CatSper current amplitudes (ICatSper, pA) and (C) Average current densities $(\mathrm{pA} / \mathrm{pF})$ recordings from sperm cells of different species as indicated; $\boldsymbol{n}$ indicates the number of individual sperm cells used. Data are Mean +/- S.E.M. Please click here to view a larger version of this figure. 

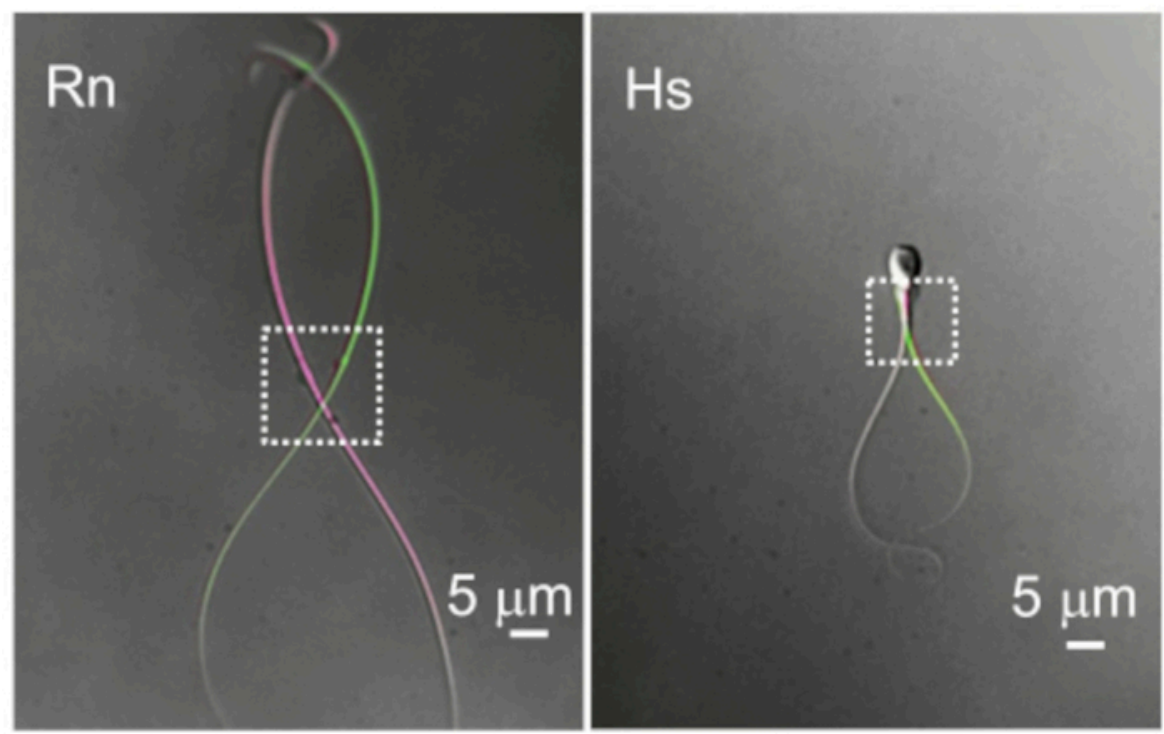

Figure 10: The difference in flagellar motility. Two representative examples of cytoplasmic droplets and flagellar motility. The overlaid images of the same rat $(\mathrm{Rn})$ and human $(\mathrm{Hs})$ sperm cells were taken at two different time points when they show the most distal flagellar deflection. Dotted rectangles indicate the region with cytoplasmic droplets and their corresponding spatial mobility. Please click here to view a larger version of this figure. 

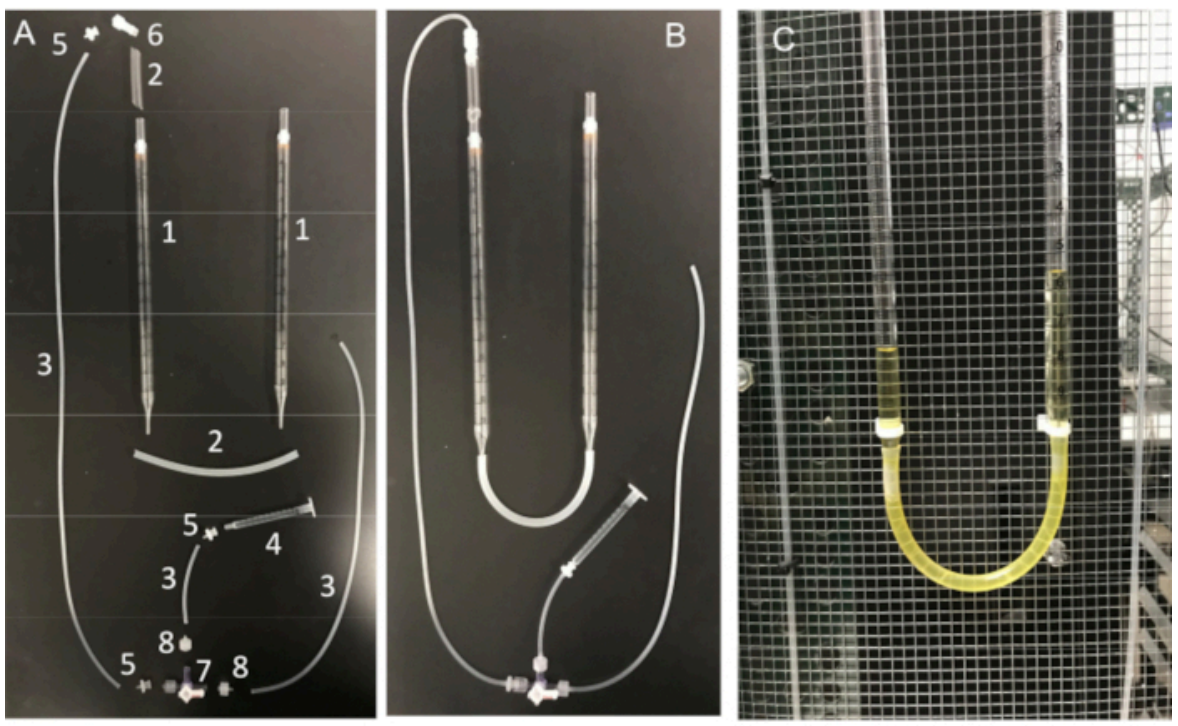

Figure 11: U-tube assembly and its essential components. (A) Components of the U-tube: (1) $10 \mathrm{~mL}$ serological pipette; (2) Silicone tubing; (3) Silicone connector tubing; (4) $1 \mathrm{~mL}$ syringe; (5) Female luer barb adapter; (6) male Luer integral lock adapter 1/8"; (7) stopcock with Luer connections; 4-way; male lock; (8) male Luer series barb adapter, 1/16". (B) Fully assembled U-tube and $(\mathbf{C})$ U-tube attached to the Faraday cage. Please click here to view a larger version of this figure. 

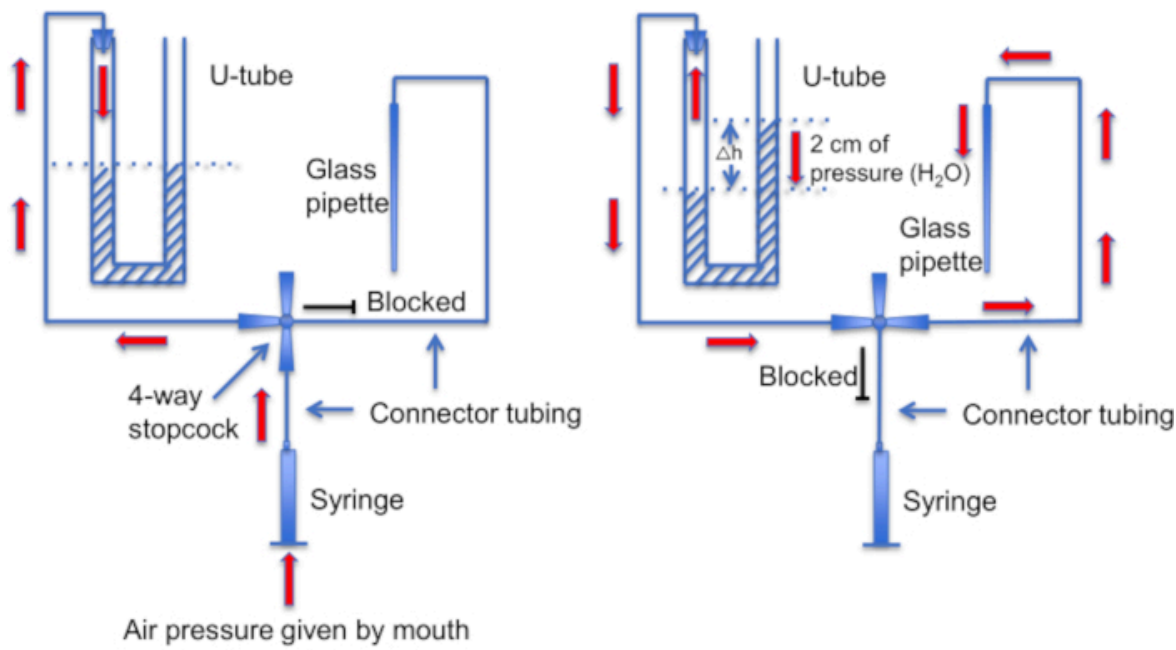

Figure 12: A schematic representation of the U-tube assembly. Left panel: Positive air pressure is provided by mouth to create a difference in liquid levels in the U-tube. The level of liquid in the right horn rises by $2 \mathrm{~cm}$. After this level difference is created, the stopcock is turned to connect the U-tube to the line leading to a recording pipette. Right panel: the higher liquid level in the right horn creates positive pressure that constantly pushes pipette solution out of the pipette tip and keeps the tip clean of debris. Please click here to view a larger version of this figure.

\begin{tabular}{|c|c|c|c|}
\hline Chemicals & Molar weight $(\mathrm{g} / \mathrm{mol})$ & $\mathrm{mM}$ & $\mathrm{g}$ for $1 \mathrm{~L}$ \\
\hline $\mathrm{NaCl}$ & 58.44 & 97.8 & $0.72 \mathrm{~g}$ \\
\hline $\mathrm{KCl}$ & 74.55 & 0.37 & $50.4 \mathrm{mg}$ \\
\hline $\mathrm{KH}_{2} \mathrm{PO}_{4}$ & 136.09 & 0.2 & $49.3 \mathrm{mg}$ \\
\hline $\mathrm{MgSO}_{4} \times 7 \cdot \mathrm{H}_{2} \mathrm{O}$ & 246.48 & 2 & $0.294 \mathrm{~g}$ \\
\hline $\mathrm{CaCl}_{2} \times 2 \cdot \mathrm{H}_{2} \mathrm{O}$ & 147.02 & 20 & $4.766 \mathrm{~g}$ \\
\hline $\mathrm{HEPES}$ & 238.3 & 3 & $0.540 \mathrm{~g}$ \\
\hline Glucose & 180.2 & 20 & $3 \mathrm{ml}$ \\
\hline Sodium lactate $(60 \% \mathrm{w} / \mathrm{w})$ & 112.06 & 0.4 & $44 \mathrm{mg}$ \\
\hline Sodium pyruvate & 110 & 5 & \\
\hline
\end{tabular}

Table 1: Human tubular fluid (HTF) solution 


\begin{tabular}{|c|c|c|c|}
\hline Chemicals & Molar weight $(\mathrm{g} / \mathrm{mol})$ & $\mathrm{mM}$ & $\mathrm{g}$ for $1 \mathrm{~L}$ \\
\hline $\mathrm{NaCl}$ & 58.44 & 135 & $7.889 \mathrm{~g}$ \\
\hline $\mathrm{KCl}$ & 74.55 & 2 & $0.373 \mathrm{~g}$ \\
\hline $\mathrm{CaCl}_{2} \times 2 \cdot \mathrm{H}_{2} \mathrm{O}$ & 147.02 & 1 & $0.294 \mathrm{~g}$ \\
\hline $\mathrm{MgSO}_{4} \times 7 \cdot \mathrm{H}_{2} \mathrm{O}$ & 246.48 & 20 & $0.247 \mathrm{~g}$ \\
\hline $\mathrm{HEPES}$ & 238.3 & 5 & $4.766 \mathrm{~g}$ \\
\hline Glucose & 180.2 & 10 & $0.901 \mathrm{~g}$ \\
\hline Sodium lactate $(60 \% \mathrm{w} / \mathrm{w})$ & 112.06 & 1 & $1.5 \mathrm{ml}$ \\
\hline Sodium pyruvate & 110 & & $0.110 \mathrm{~g}$ \\
\hline
\end{tabular}

Table 2: High-Saline (HS) Solution

\begin{tabular}{|c|c|c|c|}
\hline Chemicals & Molar weight $(\mathrm{g} / \mathrm{mol})$ & $\mathrm{mM}$ & $\mathrm{g}$ (for $500 \mathrm{ml})$ \\
\hline CsMeSO3 & 228.0 & 140 & $15.960 \mathrm{~g}$ \\
\hline HEPES & 238.3 & 40 & $4.766 \mathrm{~g}$ \\
\hline EDTA & 292.24 & 1 & $0.146 \mathrm{~g}$ \\
\hline
\end{tabular}

Table 3: $\mathrm{CsMeSO}_{3}$ bath solution (Divalent Free bath solution: DVF)

\begin{tabular}{|c|c|c|c|}
\hline Chemicals & Molar weight $(\mathrm{g} / \mathrm{mol})$ & $\mathrm{mM}$ & $\mathrm{mg}(\mathrm{for} 25 \mathrm{ml})$ \\
\hline CsMeSO3 & 228.0 & 70 & $741 \mathrm{mg}$ \\
\hline HEPES & 238.3 & 2 & $13 \mathrm{mg}$ \\
\hline EDTA & 292.24 & 3 & $28.5 \mathrm{mg}$ \\
\hline EGTA & 380.35 & 1 & $25 \mu \mathrm{mg}$ \\
\hline CsCl & 1 M solution & & 25 \\
\hline
\end{tabular}

Table 4: $\mathrm{CsMeSO}_{3}$ pipette solution 


\section{Discussion}

We describe a detailed protocol to perform electrophysiological recordings from sperm cells of various species. Given the physiological significance of ion channels and electrogenic transporters for spermatozoa, this technique is a powerful tool to study sperm cell physiology as well as defects that lead to male infertility. The experimenter might find the execution of this technique challenging at first, but with perseverance and endurance, success follows.

Mammalian spermatozoa are long (usually $>50 \mu \mathrm{m}$ ), narrow, and highly motile. The basal beat frequency (BF) of mammalian spermatozoa varies greatly with values averaging from $4 \mathrm{~Hz}$ (mouse ${ }^{69}$ ), 7-15 Hz (boar 70,71), 11 $\mathrm{Hz}$ (rat ${ }^{72}$ ), $11-20 \mathrm{~Hz}$ (bull ${ }^{18}$ ), $24 \mathrm{~Hz}$ (rhesus macaque ${ }^{23}$ ), and up to $25 \mathrm{~Hz}$ (human ${ }^{3}$ ). The cytoplasmic droplet (CD) is the entryway for recording from sperm cells. In rodent spermatozoa the $C D$ is often distal but moves alongside the flagellum (Figure 10), creating an additional obstacle to recording. However, in human sperm cells the CD is more commonly located near the head. The key components of a successful sperm patch-clamp are therefore excellent optics to enable a clear, sharp view of the $C D$ and a highly precise micromanipulator system without drift or vibration. An initial high rate of failure is expected and is normal within the first several days of sperm patch clamp. We recommend routine practice involving numerous attempts per week. Achieving several recordings per day per week will establish a routine and improve motor skills.

Until recently, the identification and pharmacological characterization of sperm ion channels was hindered by an inability to study them directly. The field largely relied on immunocytochemistry studies, which often suffer from nonspecificity of antibodies and/or the lack of corresponding genetic models. To study calcium channels, the classical calcium imaging method has been widely used, which has its own advantages and limitations ${ }^{73,74,75,76,77}$. While calcium imaging is a relatively easy method that is applicable for medium-to-high throughput studies ${ }^{78,79,80,81}$ and is less invasive, it requires relatively intact cells, and hence poses a hurdle to dissect the function of ion channels decoupled from intracellular signaling cascades or to distinguish them from calcium ion exchangers. Additionally, it is difficult to control membrane potential and therefore, harder to exclude the contribution of the voltage-gated calcium channels. Among several advantages of calcium fluorometry is the use of calcium ratiometric dyes that allows precise measurement of the changes in calcium ion concentration. At the same time, one must be aware that the sensitivity of these dyes can vary based on the changes of intracellular $\mathrm{pH}$.

Below we describe the critical steps within the protocol, including troubleshooting steps of the method. It is essential to use only pure reagents for the preparations of the experimental solutions, as even small contamination with undesirable ions (such as magnesium or heavy metals) can impair the detection of monovalent currents. Given the small size of the sperm cells, one can expect a relatively low number of ion channels per cell. Hence, the net current ranges from a few $\mathrm{pA}$ to several hundred $\mathrm{pA}$. Therefore, the internal electrical noise of the rig must be minimal to ensure detection of small currents, and the use of drift-free equipment is highly recommended. In order to distinguish a specific conductance from electrical noise and background leak, the recording apparatus and grounding system must be maximized. This is achieved by properly grounding the rig to avoid any electrical interference ${ }^{82}$. The use of a Faraday cage is highly recommended to protect from electrical interference produced by a variety of electrical 
devices, such as building lights and in-wall electrical wiring. It is essential that all electrically powered components of the rig, including the computer keyboard and mouse radiate little or no electrical $(50 \mathrm{~Hz}$ or $60 \mathrm{~Hz}$ ) noise and that all components of the rig are properly grounded. The electrical noise in the whole-cell configuration when all ion channels are closed should be $<0.5-1 \mathrm{pA}$.

Another important point is to monitor correct osmolarities of the working solutions. The composition of the intra- and extracellular solutions must be precisely determined and their osmolarities measured correctly. The extracellular solution must be slightly hypotonic in comparison to the pipette solution as it leads to miniscule cell swelling and prevents the pipette being clogged by the sperm membrane. Note: if the pipette solution is too hypertonic and differs from the bath solution more than $10 \mathrm{mOsm}$, excessive cell swelling, and seal rupture ensues. As a result, the cell will be fragile and the gigaseal lost within seconds after break-in. In our experience, inaccurate solution preparation is one of the most common mistakes that prevents successful patch-clamping.

Another potential obstacle to avoid is plasticizer/phthalatecontaining plastic, as well as mineral oil lubricated syringes. The tubing, syringes and all plastic equipment that encounters solutions, and hence sperm cells, should not leach plasticizers or other environmental toxins or oils, since such chemicals can significantly alter ion channel activity. We use small diameter Teflon tubing as the main perfusion line. Teflon (PTFE) has few leachable compounds but is rather stiff. Flexible connections are made of high purity silicon tubing that fits over the Teflon tubing. All syringes used for the perfusion system lack any lubricant, since the mineral oil or other lubricating additives can interfere with ion channel recording.
We cannot overstate the importance of using the right glass and pulling the correct micropipette shape. Hence, the optimal fabrication of glass micropipettes is a prerequisite for successful patching. We use glass micropipettes made only from borosilicate glass containing a filament for better solution filling. The tip of the pipettes must be fire-polished to provide the ideal tight seal. Pipette tips that exceed $2 \mu \mathrm{m}$ in diameter (and hence have a resistance of $10 \mathrm{M} \Omega$ or below) are generally not suitable for sperm cell patch-clamp.

Another important step is to ensure that the micropipette tip be kept clean of any debris or air bubbles before seal formation. This is a difficult task given that the micropipette is loaded into a solution full of motile cells. One factor that helps avoid accidental "bumping" of the pipette into free-swimming sperm cells, is to use a constant perfusion to wash away all nonadherent cells. Another tool is a home-made "U-tube" that allows one to switch between positive and negative pressure modes to keep the tip clean (Figure 11 and Figure 12).

As sperm cells vary greatly in the shape and size of their cytoplasmic droplets (CD), it is important to pick a droplet with suitable morphology. As shown on Figure 2, only CDs that are small (1-3 $\mu \mathrm{m})$, smooth, uniform, and not overly swollen are suitable for patch-clamp. Tiny, one-sided; "bloated", fully transparent CDs produce weak or no seals. CDs that have large soluble particles inside may clog the recording pipette. When testicular mouse spermatozoa enter the epididymis, their CDs are located in the neck region, close to the head. As they travel through the epididymis, their CDs move along the midpiece and eventually arrive at the connection between the midpiece and principal piece (the annulus) when spermatozoa reach the cauda epididymis. Therefore, as mentioned above in sperm cells isolated from the corpus epididymis, the CD is usually located close to the center of 
the midpiece. In caudal cells, the CD can usually be found close to the annulus (Figure $\mathbf{2 C}$ ). For human sperm, the $C D$ is located in the neck region (Figure 2A,B).

While this is not an issue for spermatozoa isolated from laboratory animals, significant variability exists between human donors. Variation in sperm quality within the same donor mainly affects the quality of the sperm plasma membrane and sometimes makes seal formation relatively difficult. There is less variability in ion channel behavior and pharmacology, factors that probably correlate with individual genetics or physiology. One has to be persistent and assess samples from various donations during multiple days, as well as rely on multiple human donor participants. Working with human material requires extra patience, since donated sperm vary greatly in sperm quality within the same donor, depending on various environmental factors. We recommend assessing samples from various donation days to make a final decision on the donor status. While ejaculated purified spermatozoa are generally suitable for electrophysiology within hours (up to 12 hours after isolation for human sperm), epididymal murine sperm cells are suitable for patching only within a 2-hour window after isolation.

And last, but not least, gigaseal formation differs among sperm cells. For murine/rodent sperm cells, gigaseal formation happens almost instantaneously, while several seconds (and sometimes up to a minute) are required to form a gigaseal with a human sperm. Often the initial suction results in an input resistance ranging from $200 \mathrm{M} \Omega$ to 800 $\mathrm{M} \Omega$. Switching holding potential to $-60 \mathrm{mV}$ and providing "Membrane Test" short pulses up to $10 \mathrm{mV}$ often helps rescue gigaseal formation (through voltage field induced movement of the membrane in the pipette).
The sperm cell patch clamp technique enables the detailed study of specific ion channels in their natural expression system. The success of the technique depends on proper equipment, high quality viable sperm cells, pure reagents, basic electrophysiology skills, patience, and persistence. The method opens new frontiers in sperm physiology by studying ion channel evolutionary diversity, mechanisms of their regulation, and alterations in their function as they move from the male to the female reproductive tract and are altered by exogenous conditions, such as $\mathrm{pH}$ and ligands.

\section{Disclosures}

The authors have nothing to disclose.

\section{Acknowledgments}

This work was supported by NIH Grant R01GM111802, Pew Biomedical Scholars Award 00028642, Alfred P. Sloan Award FR-2015-65398, and Packer Wentz Endowment Will (to P.V.L.). This work was also supported by Deutsche Forschungsgemeinschaft (German Research Foundation) 368482240/GRK2416 (to N.M.) and by China Scholarship Council Fellowship to B.L. We thank Dr. Dan Feldman for sharing rat tissue, Katie Klooster and Stuart Meyers from UC Davis for help with primate sperm cells acquisition, and Steven Mansell for the help with data acquisition analysis from boar and bull sperm cells.

\section{References}

1. Sakmann, B., Neher, E. Patch clamp techniques for studying ionic channels in excitable membranes. Annual Review Physiology. 46, 455-472 (1984).

2. Kirichok, Y., Navarro, B., Clapham, D. E. Whole-cell patch-clamp measurements of spermatozoa reveal an 
alkaline-activated Ca2+ channel. Nature. 439, 737-740 (2006).

3. Smith, J. F. et al. Disruption of the principal, progesterone-activated sperm $\mathrm{Ca} 2+$ channel in a CatSper2-deficient infertile patient. Proceedings of the National Academy of Science U. S. A. 110, 6823-6828 (2013).

4. Hille, B. Ion Channels of Excitable Membranes 3rd Edition. 3 edn, Sinauer Associates - an imprint of Oxford University Press. (2001).

5. Molleman, A. An Introductory Guide to Patch Clamp Electrophysiology. John Wiley \& Sons Ltd. (2003).

6. Darszon, A. et al. Measuring ion fluxes in sperm. Methods Cell Biology. 74, 545-576 (2004).

7. Lishko, P. V. et al. The control of male fertility by spermatozoan ion channels. Annual Review Physiology. 74, 453-475 (2012).

8. Lishko, P., Clapham, D. E., Navarro, B., Kirichok, Y. Sperm patch-clamp. Methods in Enzymology. 525, 59-83 (2013).

9. Ren, D., Xia, J. Calcium signaling through CatSper channels in mammalian fertilization. Physiology (Bethesda). 25, 165-175 (2010).

10. Darszon, A., Labarca, P., Nishigaki, T., Espinosa, F. Ion channels in sperm physiology. Physiological Reviews. 79, 481-510 (1999).

11. Cook, S. P., Brokaw, C. J., Muller, C. H., Babcock, D. F. Sperm chemotaxis: egg peptides control cytosolic calcium to regulate flagellar responses. Developmental Biology. 165, 10-19 (1994).

12. Miller, R. L. Chemotaxis of the spermatozoa of Ciona intestinalis. Nature. 254, 244-245 (1975).
13. Goltz, J. S., Gardner, T. K., Kanous, K. S., Lindemann, C. B. The interaction of $\mathrm{pH}$ and cyclic adenosine $3^{\prime}, 5^{\prime}$-monophosphate on activation of motility in Triton X-100 extracted bull sperm. Biology of Reproduction. 39, 1129-1136 (1988).

14. Gibbons, B. H., Gibbons, I. R. Flagellar movement and adenosine triphosphatase activity in sea urchin sperm extracted with triton X-100. Journal of Cell Biology. 54, 75-97 (1972).

15. Carr, D. W., Acott, T. S. Intracellular pH regulates bovine sperm motility and protein phosphorylation. Biology of Reproduction. 41, 907-920 (1989).

16. Babcock, D. F., Rufo, G. A., Jr., Lardy, H. A. Potassium-dependent increases in cytosolic $\mathrm{pH}$ stimulate metabolism and motility of mammalian sperm. Proceedings of the National Academy of Science U.S. A. 80, 1327-1331 (1983).

17. Zeng, Y., Oberdorf, J. A., Florman, H. M. pH regulation in mouse sperm: identification of $\mathrm{Na}(+)-, \mathrm{Cl}(-)-$, and HCO3(-)-dependent and arylaminobenzoate-dependent regulatory mechanisms and characterization of their roles in sperm capacitation. Developmental Biolgy. 173, 510-520 (1996).

18. Lindemann, C. B., Gibbons, I. R. Adenosine triphosphate-induced motility and sliding of filaments in mammalian sperm extracted with Triton X-100. Journal of Cell Biol.ogy. 65, 147-162 (1975).

19. Lindemann, C. B., Goltz, J. S., Kanous, K. S. Regulation of activation state and flagellar wave form in epididymal rat sperm: evidence for the involvement of both $\mathrm{Ca} 2+$ and cAMP. Cell Motility and Cytoskeleton. 8, 324-332 (1987). 
20. Brokaw, C. J. Calcium-induced asymmetrical beating of triton-demembranated sea urchin sperm flagella. Journal of Cell Biology. 82, 401-411 (1979).

21. Suarez, S. S. Control of hyperactivation in sperm. Human Reproduction Update. 14, 647-657 (2008).

22. Suarez, S. S., Varosi, S. M., Dai, X. Intracellular calcium increases with hyperactivation in intact, moving hamster sperm and oscillates with the flagellar beat cycle. Proceedings of the National Academy of Science U. S. A. 90, 4660-4664 (1993).

23. Ishijima, S., Mohri, H., Overstreet, J. W., Yudin, A. I. Hyperactivation of monkey spermatozoa is triggered by Ca2+ and completed by cAMP. Molecular Reproduction and Development. 73, 1129-1139 (2006).

24. Ho, H. C., Granish, K. A., Suarez, S. S. Hyperactivated motility of bull sperm is triggered at the axoneme by $\mathrm{Ca} 2+$ and not cAMP. Developmental Biology. 250, 208-217 (2002).

25. Schreiber, M. et al. Slo3, a novel pH-sensitive $\mathrm{K}+$ channel from mammalian spermatocytes. Journal of Biological Chemisty. 273, 3509-3516 (1998).

26. Santi, C. M. et al. The SLO3 sperm-specific potassium channel plays a vital role in male fertility. FEBS Letters. 584, 1041-1046 (2010).

27. Zeng, X. H., Yang, C., Kim, S. T., Lingle, C. J., Xia, X. M. Deletion of the Slo3 gene abolishes alkalization-activated $\mathrm{K}+$ current in mouse spermatozoa. Proceedings of the National Academy of Science U. S. A. 108, 5879-5884 (2011).

28. Navarro, B., Kirichok, Y., Clapham, D. E. KSper, a $\mathrm{pH}$-sensitive $\mathrm{K}+$ current that controls sperm membrane potential. Proceedings of the National Academy of Science U. S. A. 104, 7688-7692 (2007).

29. Navarro, B., Kirichok, Y., Chung, J. J., Clapham, D. E. Ion channels that control fertility in mammalian spermatozoa. International Journal of Developmental Biology. 52, 607-613 (2008).

30. Quill, T. A., Ren, D., Clapham, D. E., Garbers, D. L. A voltage-gated ion channel expressed specifically in spermatozoa. Proceedings of the National Academy of Science U. S. A. 98, 12527-12531 (2001).

31. Ren, D. et al. A sperm ion channel required for sperm motility and male fertility. Nature. 413, 603-609 (2001).

32. Carlson, A. E. et al. Identical phenotypes of CatSper1 and CatSper2 null sperm. Journal of Biological Chemistry. 280, 32238-32244 (2005).

33. Carlson, A. E. et al. CatSper1 required for evoked $\mathrm{Ca} 2+$ entry and control of flagellar function in sperm. Proceedings of the National Academy of Science U. S. A. 100, 14864-14868 (2003).

34. Quill, T. A. et al. Hyperactivated sperm motility driven by CatSper2 is required for fertilization. Proceedings of the National Academy of Science U. S. A. 100, 14869-14874 (2003).

35. Xia, J., Reigada, D., Mitchell, C. H., Ren, D. CATSPER channel-mediated $\mathrm{Ca} 2+$ entry into mouse sperm triggers a tail-to-head propagation. Biology of Reproduction. 77, $551-559$ (2007).

36. Chung, J. J. et al. Structurally distinct $\mathrm{Ca}(2+)$ signaling domains of sperm flagella orchestrate tyrosine phosphorylation and motility. Cell. 157, 808-822 (2014). 
37. Chung, J. J. et al. CatSperzeta regulates the structural continuity of sperm $\mathrm{Ca} 2+$ signaling domains and is required for normal fertility. eLife. 6, 23082 (2017).

38. Hwang, J. Y. et al. Dual Sensing of Physiologic $\mathrm{pH}$ and Calcium by EFCAB9 Regulates Sperm Motility. Cell. 177, 1480-1494 e1419 (2019).

39. Lishko, P. V., Botchkina, I. L., Kirichok, Y. Progesterone activates the principal $\mathrm{Ca} 2+$ channel of human sperm. Nature. 471, 387-391 (2011).

40. Strünker, T. et al. The CatSper channel mediates progesterone-induced $\mathrm{Ca} 2+$ influx in human sperm. Nature. 471, 382-386 (2011).

41. Sumigama, S. et al. Progesterone accelerates the completion of sperm capacitation and activates CatSper channel in spermatozoa from the rhesus macaque. Biology of Reproduction. 93, 130 (2015).

42. Chung, J. J., Navarro, B., Krapivinsky, G., Krapivinsky, L., Clapham, D. E. A novel gene required for male fertility and functional CATSPER channel formation in spermatozoa. Nature Communication. 2, 153 (2011).

43. Wang, H., Liu, J., Cho, K. H., Ren, D. A novel, single, transmembrane protein CATSPERG is associated with CATSPER1 channel protein. Biology of Reproduction. 81, 539-544 (2009).

44. Qi, H. et al. All four CatSper ion channel proteins are required for male fertility and sperm cell hyperactivated motility. Proceedings of the National Academy of Science U. S. A. 104, 1219-1223 (2007).

45. Liu, J., Xia, J., Cho, K. H., Clapham, D. E., Ren, D. CatSperbeta, a novel transmembrane protein in the CatSper channel complex. Journal of Biological Chemistry. 282, 18945-18952 (2007).
46. Jin, J. et al. Catsper3 and Catsper4 are essential for sperm hyperactivated motility and male fertility in the mouse. Biology of Reproduction. 77, 37-44 (2007).

47. Lobley, A., Pierron, V., Reynolds, L., Allen, L., Michalovich, D. Identification of human and mouse CatSper3 and CatSper4 genes: characterisation of a common interaction domain and evidence for expression in testis. Reproductive Biology and Endocrinology. 1, 53 (2003).

48. Mundt, N., Spehr, M., Lishko, P. V. TRPV4 is the temperature-sensitive ion channel of human sperm. eLife. 7, 35853 (2018).

49. Zeng, X. H., Yang, C., Xia, X. M., Liu, M., Lingle, C. J. SLO3 auxiliary subunit LRRC52 controls gating of sperm KSPER currents and is critical for normal fertility. Proceedings of the National Academy Science U. S. A. 112, 2599-2604 (2015).

50. Mansell, S. A., Publicover, S. J., Barratt, C. L., Wilson, S. M. Patch clamp studies of human sperm under physiological ionic conditions reveal three functionally and pharmacologically distinct cation channels. Molecular Human Reprodroduction. 20, 392-408 (2014).

51. Lishko, P. V., Botchkina, I. L., Fedorenko, A., Kirichok, Y. Acid extrusion from human spermatozoa is mediated by flagellar voltage-gated proton channel. Cell. 140, 327-337 (2010).

52. Miller, M. R. et al. Unconventional endocannabinoid signaling governs sperm activation via the sex hormone progesterone. Science. 352, 555-559 (2016). 
53. Brenker, C. et al. The Ca2+-activated $\mathrm{K}+$ current of human sperm is mediated by Slo3. eLife. 3, e01438 (2014).

54. Orta, G. et al. Human spermatozoa possess a calciumdependent chloride channel that may participate in the acrosomal reaction. Journal of Physiology. 590, 2659-2675 (2012).

55. Kirichok, Y., Lishko, P. V. Rediscovering sperm ion channels with the patch-clamp technique. Molecular Human Reproduction. 17, 478-499 (2011).

56. Miller, M. R. et al. Asymmetrically positioned flagellar control units regulate human sperm rotation. Cell Reports. 24, 2606-2613 (2018).

57. Espinosa, F. et al. Mouse sperm patch-clamp recordings reveal single $\mathrm{Cl}$ - channels sensitive to niflumic acid, a blocker of the sperm acrosome reaction. FEBS Letters. 426, 47-51 (1998).

58. Gu, Y., Kirkman-Brown, J. C., Korchev, Y., Barratt, C. L., Publicover, S. J. Multi-state, 4-aminopyridine-sensitive ion channels in human spermatozoa. Developmental Biology. 274, 308-317 (2004).

59. Jimenez-Gonzalez, M. C., Gu, Y., Kirkman-Brown, J., Barratt, C. L., Publicover, S. Patch-clamp 'mapping' of ion channel activity in human sperm reveals regionalisation and co-localisation into mixed clusters. Journal of Cell Physiology. 213, 801-808 (2007).

60. Khasin, L. G. et al. The impact of di-2-ethylhexyl phthalate on sperm fertility. Frontiers in Cell and Developmental Biology. 8, 426 (2020).

61. Tavares, R. S. et al. p,p'-DDE activates CatSper and compromises human sperm function at environmentally relevant concentrations. Human Reproduction. 28, 3167-3177 (2013).

62. Schiffer, C. et al. Direct action of endocrine disrupting chemicals on human sperm. EMBO Reports. 15, 758-765 (2014).

63. Skinner, W. M., Mannowetz, N. Lishko, P. V. Roan, N. R. Single-cell motility analysis of tethered human spermatozoa. Bio-Protocols. 9, 5 (2019).

64. World Health Organization Laboratory Manual for the Examination and Processing of Human Semen. 5th edn, (2010).

65. Mannowetz, N., Naidoo, N. M., Choo, S. A., Smith, J. F., Lishko, P. V. Slo1 is the principal potassium channel of human spermatozoa. eLife. 2, e01009 (2013).

66. Miller, M. R., Mansell, S. A., Meyers, S. A., Lishko, P. V. Flagellar ion channels of sperm: similarities and differences between species. Cell Calcium. 58, 105-113 (2015).

67. Berger, T. K. et al. Post-translational cleavage of Hv1 in human sperm tunes $\mathrm{pH}$ - and voltage-dependent gating. Journal Physiology. 595, 1533-1546 (2017).

68. Chavez, J. C. et al. SLO3 K+ channels control calcium entry through CATSPER channels insperm. Journal Biological Chemistry. 289 (46) 32266-32275(2014).

69. Wennemuth, G., Babcock, D. F., Hille, B. Calcium clearance mechanisms of mouse sperm. The Journal of General Physiology. 122, 115-128 (2003).

70. de Wagenaar, B. et al. Spermometer: electrical characterization of single boar sperm motility. Fertility and Sterility. (2016).

71. Satake, N., Elliott, R. M., Watson, P. F., Holt, W. V. Sperm selection and competition in pigs may be mediated by 
the differential motility activation and suppression of sperm subpopulations within the oviduct. The Journal of Experimental Biology. 209, 1560-1572 (2006).

72. Dostal, L. A., Faber, C. K., Zandee, J. Sperm motion parameters in vas deferens and cauda epididymal rat sperm. Reproductive Toxicology. 10, 231-235 (1996).

73. Umehara, T. et al. The acceleration of reproductive aging in Nrg1(flox/flox) ;Cyp19-Cre female mice. Aging Cell. 16, 1288-1299 (2017).

74. Florman, H. M., Tombes, R. M., First, N. L., Babcock, D. F. An adhesion-associated agonist from the zona pellucida activates $\mathrm{G}$ protein-promoted elevations of internal $\mathrm{Ca} 2+$ and $\mathrm{pH}$ that mediate mammalian sperm acrosomal exocytosis. Developmental Biology. 135, 133-146 (1989).

75. Carlson, A. E., Hille, B., Babcock, D. F. External Ca2+ acts upstream of adenylyl cyclase SACY in the bicarbonate signaled activation of sperm motility. Developmental Biology. 312, 183-192 (2007).

76. Cook, S. P., Babcock, D. F. Activation of Ca2+ permeability by cAMP is coordinated through the $\mathrm{pHi}$ increase induced by speract. Journal of Biological Chemistry. 268, 22408-22413 (1993).

77. Babcock, D. F., Pfeiffer, D. R. Independent elevation of cytosolic [Ca2+] and $\mathrm{pH}$ of mammalian sperm by voltagedependent and pH-sensitive mechanisms. Journal of Biological Chemistry. 262, 15041-15047 (1987).

78. Rehfeld, A. et al. Medium-throughput screening assays for assessment of effects on Ca2+-signaling and acrosome reaction in human sperm. Journal of Visualized Experiments .(145), e59212 (2019).
79. Rehfeld, A. et al. Chemical UV filters can affect human sperm function in a progesterone-like manner. Endocrine Connections. 7 (1), 16-25 (2017).

80. Martins da Silva, S. J. et al. Drug discovery for male subfertility using high-throughput screening: a new approach to an unsolved problem. Human Reproduction. 32, 974-984 (2017).

81. Alasmari, W. et al. The clinical significance of calcium-signalling pathways mediating human sperm hyperactivation. Human Reproduction. 28, 866-876 (2013).

82. Jim Rae, R. L. Optimizing your Axopatch 200B setup for low-noise recording. Axobits. 38, (2003). 